\title{
Duplex Guided Foam Sclerotherapy Versus Surgery in Management of Primary Varicose Veins
}

\author{
Walid M Gamal*, Abdelraheem Fathy Mohamed and M Khalil Elammary \\ Vascular, Surgery Department, South Valley University, Qena, Egypt \\ General Surgery Department, Qena University Hospital, Egypt
}

\begin{abstract}
Background: Varicose veins is a major problem among adult population. It has a major effect on life quality as well as healthcare system resources, we aim in this study to compare ultrasound guided foam sclerotherapy (UGFS) with surgery in management of primary varicose veins patients and to measure patients' satisfaction with either modalities.

Methods: 100 lower limbs of 100 patients with great saphenous vein (GSV) incompetence were prospectively randomized to undergo either surgical treatment or foam sclerotherapy. Clinical, etiological, anatomical and pathophysiological (CEAP) Classification and the Venous Clinical Severity Score (VCSS) were completed and investigated with a follow-up period of 1 year.

Results: Total occlusion of great saphenous vein (GSV) was $88 \%$ in foam group as well as in the surgery group, recurrence rate in the foam group was $6 \%$ as well as in surgery group. Patient satisfaction at 1 year was $94 \%$ in foam group while in surgery group it was $90 \%$. There were no statistical significant differences in follow up regarding VCSS, recurrence, patient satisfaction between both groups at 1 month, 6 months and 1 year ( $p$ value $>0.001)$.

Conclusion: Surgical treatment and UGFS achieved elevated rates of total occlusion of GSV incompetence with no significant difference. Both treatments led to significant improvements in VCSS, demonstrating improvements in clinical outcomes. UGFS is a valid noninvasive modality in management of great saphenous vein incompetence and is comparable to surgery.
\end{abstract}

Keywords: Ultrasound guided foam sclerotherapy; Varicose veins surgery; VCSS; CEAP

\section{Introduction}

Multiple studies show that at least one quarter of the adult population have varicose veins [1]. This condition is often correlated with great saphenous vein (GSV) reflux [1,2]. Varicose veins disease has a major effect on quality of life, as well as on the resources and budgets of healthcare systems [3]. For decades, the ideal management was surgical removal of the GSV. Research comparing liquid sclerotherapy and surgery for treatment of GSV incompetence showed that surgery was more effective $[4,5]$.

Long-term results of surgery indicated recurrence rates of between 21 and $26 \%$ after 3 years of follow-up and $60 \%$ after 34 years [6-8]. However, recently there is an increased demand for minimally invasive and less expensive procedures such as ultrasound-guided foam sclerotherapy (UGFS), endovenous laser ablation (EVLA) and radiofrequency ablation (RFA) [9].

UGFS is a variant of liquid sclerotherapy, in which the liquidair mixture (foam) is injected into varicose veins under ultrasound guidance. In comparison with liquid sclerotherapy, UGFS is more efficient $[10,11]$. UGFS has a reported successful result of $75-85 \%$ after 1 year and $69 \%$ after 2 years of follow-up [12-14]. Advantages of this treatment are that it is less invasive, reduces healthcare costs, and is associated with a shorter recovery time than surgery [15,16], making UGFS an appealing substitution to operations for varicose veins management.

The aim of our work is to compare ultrasound guided foam sclerotherapy (UGFS) with surgery in treatment of patients with primary chronic venous insufficiency.

\section{Materials and Methods}

This Prospective randomized controlled study was carried out in Department of vascular surgery, Qena University Hospital, South Valley University, comparing the effectiveness of surgery and UGFS in management of patients with incompetent saphenofemoral junction. Patients attending to the vascular surgery outpatient clinic in Qena university hospital were included in the study. Patients were chosen based on clinical history, physical examination, duplex ultrasound and CEAP classification and patients who gave written consent were recruited in the study.

\section{Inclusion criteria}

Patients of age between 18 and 60 years were recruited. No previous management of varicose veins and patients with primary varicose veins only with the following criteria (the clinical C2-C3, Etiological reflux, Anatomic superficial long saphenous and Pathophysiologic reflux) according to (CEAP) classification.

\section{Exclusion criteria}

Patients with primary varicosities involving both the long saphenous

*Corresponding author: Dr. Walid M Gamal, MD, Vascular Surgery Department, Qena University Hospital, South Valley University, Qena, Egypt, Tel: 00201005602090; E-mail: walidgamal@yahoo.com

Received June 08, 2017; Accepted July 15, 2017; Published July 20, 2017

Citation: Gamal WM, Mohamed AF (2017) Duplex Guided Foam Sclerotherapy Versus Surgery in Management of Primary Varicose Veins. J Vasc Med Surg 5 325. doi: 10.4172/2329-6925.1000325

Copyright: @ 2017 Gamal WM, et al. This is an open-access article distributed under the terms of the Creative Commons Attribution License, which permits unrestricted use, distribution, and reproduction in any medium, provided the original author and source are credited. 
vein (LSV)and short saphenous vein (SSV), acute deep vein thrombosis (DVT), thrombophilia, allergy to sclerosant agent, bronchial asthma, post-thrombotic syndrome, morbid obesity, pregnancy, peripheral arterial insufficiency (ankle brachial index $<0.8$ ), diabetic patients with peripheral neuropathy or ulceration, those with a patent foramen ovale and malignancy.

All the selected patients provided with detailed information related to conventional surgery and UGFS. Only one leg per patient will be involved in the study and in subjects with bilateral varicose veins the most severely affected limb was chosen and suspected to randomization.

Patients who agreed to take part in the study and who gave (informed) consent were randomly allocated to one of the treatment groups, the study was approved by local medical ethics committee of Qena University Hospital and randomization was done by asking the patients to choose from sealed envelopes. Then patients classified to:

Group 1: 50 patients managed by conventional surgical treatment.

Group 2: 50 patients managed by duplex-guided foam sclerotherapy.

\section{Conventional surgery}

Saphenofemoral junction ligation combined with saphenous stripping and phlebectomy for saphenous tributaries and ligation of incompetent perforating veins were done. The treated limbs will be bandaged at once postoperative by inelastic bandages. After 2 days, the bandages will be replaced by above knee elastic compression stockings with a compression for 3 months.

\section{Ultrasound-guided foam sclerotherapy}

Pretreatment skin marking over incompetent truncal veins and superficial varicosities will be marked on the skin using duplex ultrasound. The patient then put in a flat position for GSV cannulation. Peripheral intravenous catheters will be inserted under direct duplex guidance. According to the size and depth of the target vein, 18-22G cannulae (green, pink or blue) will be used. Once all cannulae were secured, the leg will be elevated (to empty the veins) for injection of the foam.

All cannula should be flushed with normal saline to ensure that they were not dislodged during the changes in leg position. Sclerosant foam will be prepared by Tessari's method using two $5 \mathrm{~mL}$ syringes connected by a three-way stopcock and comprised $1 \mathrm{~m}$ of sclerosing agent (ethanolamine oleate) and $4 \mathrm{~mL}$ of air.

Foam injected in $5 \mathrm{~mL}$, and its distribution and resultant venous spasm observed by duplex ultrasound, minimum 30 seconds left between each injection. After each injection patients will be asked for dorsi-and plantar-flexion of their ankle many times to get rid of any foam that might have passed to the deep venous system.

When all the trunks, tributary veins and the varices were in spasm and filled with foam, the cannulae will be removed and compression was applied with the leg still elevated. A roll was put in directly along the line of the previously marked saphenous trunk and superficial varices and kept in place using bandage. The bandage then secured with $100 \mathrm{~mm}$ wide adhesive tape, this regimen produce direct compression over the truncal veins.

Above knee class II compression stocking was put in over the bandage. The bandaging is left in place for five to ten days, depending on the veins' size then it was removed and the class II stocking used alone for further three weeks. After the procedure the patients were asked to walk for around 10 minutes and then were informed to walk for five minutes at least during every waking hour while the bandages will be in place. Patients had been given a contact telephone number to use if they experienced severe discomfort or had any other matters following treatment.

\section{Follow-up}

All patients had been seen at 1, 6 and 12 months post management in the outpatient clinic, comparing the effect of foam sclerotherapy and operation on venous symptoms (varicose vein severity score), comparing complications and side-effects after the incompetent great saphenous vein treatment such as early infection, hematoma, paraesthesia, pain at the site of injection, headache, visual disturbance, thrombo-phlebitis, DVT, pulmonary embolism, hyperpigmentation, telangiectasia matting. Patients also have been asked about their satisfaction regarding the procedure done and their answers were recorded.

Post-sclerotherapy follow-up using duplex ultrasound to measure the effectiveness of foam sclerotherapy was also done. The results will be classified as follows: complete occlusion: The GSV had shrunk and was occluded; partial GSV recanalization with no reflux, partial GSV recanalization with reflux and complete GSV recanalization with reflux. VCSS estimated duplex were done to evaluate occlusion of desired veins.

\section{Statistical analysis}

Differences between the 2 groups of patients with a specific outcome at 1 month, 6 months and 1 year post treatment were tested for statistical significance. Ninety-five percent confidence intervals around the difference in proportions were calculated. $\mathrm{P}<0.05$ was considered to indicate statistical significance. Only patients who underwent the allocated intervention were included in the analysis. All data were analyzed with SPSS version 17.0.

\section{Results}

The chosen outcome measures were complete occlusion of, and abolition of incompetence in the GSV on duplex ultrasound DUS (defined as technical success), and the complete absence of any visible varicose vein VV (defined as clinical success). Regarding patients' satisfaction, they were asked whether they are satisfied with the results of maneuver done or not and their answers whether yes or no were recorded.

\section{Demographic data and patient characteristics}

100 patients were randomized in this study, 50 patients for foam sclerotherapy and 50 patients to surgery, mean age was 35.97 . All subjects were assessed by CEAP, VCSS and duplex ultrasound. All patients had incompetent long saphenous vein, 92 patients classified as C2s and 8 classified as C3s, VCSS mean was 7.68, (maximum was 11 and minimum was 6). Only one limb per patient was included in this study. Regarding gender, the study included 50 males and 50 females. In the foam group 24 patients with Lt lower limb and 26 with Rt lower limb varicose veins were treated and 46 patients were CEAP class C2 and only 4 patients classified as C3. While in surgery group 26 patients with Lt lower limb varicose veins and 24 patients with Rt lower limb varicose veins were operated and 46 patients were classified as C2 and 4 patients as C3d as shown in Table 1 . 
Citation: Gamal WM, Mohamed AF (2017) Duplex Guided Foam Sclerotherapy Versus Surgery in Management of Primary Varicose Veins. J Vasc Med Surg 5: 325. doi: 10.4172/2329-6925.1000325

Page 3 of 7

\begin{tabular}{|c|c|c|c|c|}
\hline & All & Foam & Surgery & \\
\hline Randomized number & 100 & 50 & 50 & \\
\hline \multirow[t]{2}{*}{ Age (M, M, M, SD) } & Minimum & Maximum & Mean & Std. Deviation \\
\hline & 20 & 65 & 35.97 & 11.60847 \\
\hline Male & 50 & $25(50 \%)$ & $25(50 \%)$ & $25(50 \%)$ \\
\hline Female & 50 & $25(50 \%)$ & $25(50 \%)$ & \\
\hline Lt & 50 & $24(48 \%)$ & $26(52 \%)$ & \\
\hline Rt & 50 & $26(52 \%)$ & $24(48 \%)$ & \\
\hline Ceap (n, \%) & 100 & & & \\
\hline $\mathrm{C} 2$ & & $46(92 \%)$ & $46(92 \%)$ & \\
\hline $\mathrm{C} 3$ & & 4 & 4 & \\
\hline \multirow[t]{2}{*}{$\operatorname{VCSS}(\mathrm{M}, \mathrm{M}, \mathrm{M}, \mathrm{SD})$} & Minimum & Maximum & Mean & Std. Deviation \\
\hline & 6 & 11 & 7.68 & 1.46942 \\
\hline \multicolumn{5}{|l|}{ Duplex pre } \\
\hline Incompetent long saphenous vein & 100 & 50 & 50 & \\
\hline
\end{tabular}

Table 1: Demographic data and patient characteristics.

\begin{tabular}{|c|c|c|c|c|}
\hline Follow up & Total occlusion & $\begin{array}{l}\text { Partial recanalization without } \\
\text { reflux }\end{array}$ & Partial recanalization with reflux & Total recanalization \\
\hline \multicolumn{5}{|l|}{1 month } \\
\hline Foam & $46(92 \%)$ & $1(2 \%)$ & $2(4 \%)$ & $1(2 \%)$ \\
\hline Surgery & $50(100 \%)$ & 0 & 0 & 0 \\
\hline \multicolumn{5}{|l|}{6 month } \\
\hline Foam & 49 (98\%) & $1(2 \%)$ & 0 & 0 \\
\hline Surgery & 50 & 0 & 0 & 0 \\
\hline \multicolumn{5}{|l|}{1 year } \\
\hline Foam & $44(88 \%)$ & $3(6 \%)$ & $2(4 \%)$ & $1(2 \%)$ \\
\hline \multirow[t]{2}{*}{ Surgery } & $44(88 \%)$ & $3(6 \%)$ & $3(6 \%)$ & 0 \\
\hline & Minimum & Maximum & Mean & Std. Deviation \\
\hline VCSS 1 month & 2 & 4 & 2.92 & 0.67689 \\
\hline VCSS 6 month & 0 & 2 & 0.49 & 0.55949 \\
\hline Vcss 1 year & 0 & 3 & 0.2 & 0.60302 \\
\hline \multirow[t]{2}{*}{ Satisfaction } & \multirow[t]{2}{*}{ Foam } & \multirow[t]{2}{*}{ Surgery } & & $P$ value $>0.001$ \\
\hline & & & & -0.466 \\
\hline Satisfied & $47(94 \%)$ & $45(90 \%)$ & & \\
\hline Non satisfied & $3(6 \%)$ & $5(10 \%)$ & & \\
\hline
\end{tabular}

Table 2: Follow up data.

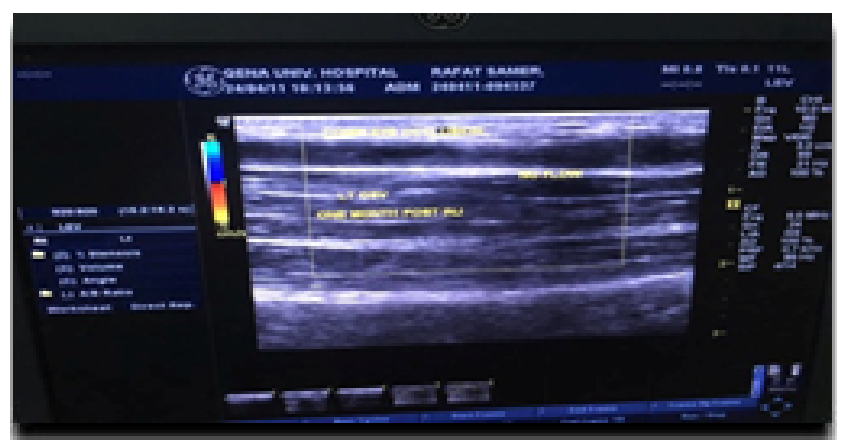

Figure 1: Foam flow within vein during procedure.

\section{Patients Follow Up}

\section{At 1 month follow up}

In foam group, $92 \%$ of patient achieve total occlusion, $2 \%$ partial recanalization without reflux, $4 \%$ partial recanalization with reflux and $2 \%$ total recanalization of these patient 3 patient receive another session of UGFS and $4^{\text {th }}$ one was satisfied with result and refuse to take another session. In surgery group 100\% achieve total occlusion at 1 month follow up (Figures 1 and 2).

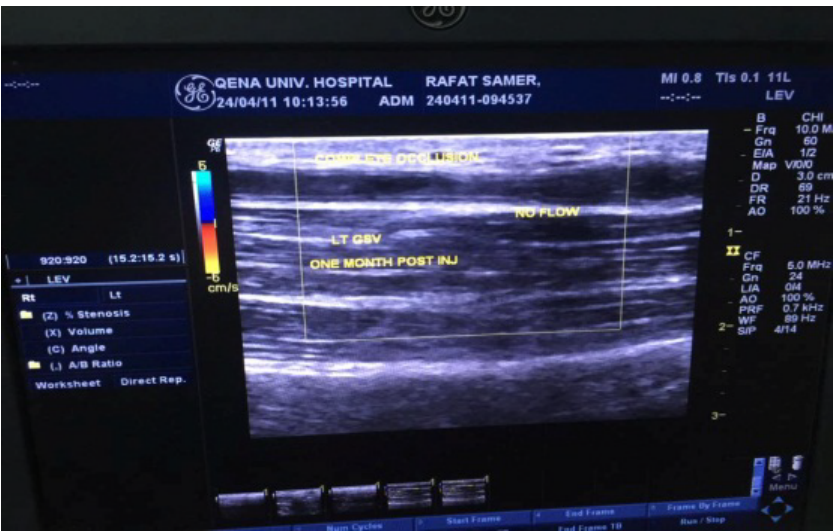

Figure 2: Complete occlusion of the vein in follow up.

\section{At 6 months follow up}

In the foam group, $98 \%$ of subjects achieve total occlusion of GSV and $2 \%$ partial recanalization without reflux and 3 of patients who received another injection session achieve total occlusion. In surgery group $100 \%$ of patients achieve total occlusion. 
Citation: Gamal WM, Mohamed AF (2017) Duplex Guided Foam Sclerotherapy Versus Surgery in Management of Primary Varicose Veins. J Vasc Med Surg 5: 325. doi: 10.4172/2329-6925.1000325

Page 4 of 7

\section{At 1 year follow up}

In foam group, $88 \%$ show total occlusion, $6 \%$ show partial recanalization without reflux, $4 \%$ show partial recanalization with reflux and $2 \%$ show total recanalization. In surgery group, $88 \%$ show total occlusion, $6 \%$ show partial recanalization without reflux and $6 \%$ show partial recanalization with reflux. All patients with complete recanalization and partial recanalization with reflux both considered treatment failure in foam group the failure was $6 \%$ and it is the same in surgery group probably because of neorevascularization or patient return to previous activities. Recurrence rate in foam group is $6 \%$ as well as in surgery group (Table 2 and Figure 3 ).

\section{Follow up of VCSS}

At 1 month mean value was 2.92, (minimum 2 and maximum 4)

At 6 months mean value was 49, (minimum 0 and maximum 2)

At 1 year mean value was 2 , (minimum 0 and maximum 3 )

\section{Patient satisfaction}

In foam group, patient satisfaction at 1 year was $94 \%$ while $6 \%$ were unsatisfied while in surgery group $90 \%$ of patients were satisfied while $10 \%$ were unsatisfied with no significant difference as $\mathrm{p}$ value $>0.001$ (0.466).

\section{Differences between groups}

No significant differences between groups were found in preoperative duplex examination, side, VCSS, CEAP classification or sex. No significant difference between groups in follow up parameters (Table 3 and Figure 4).

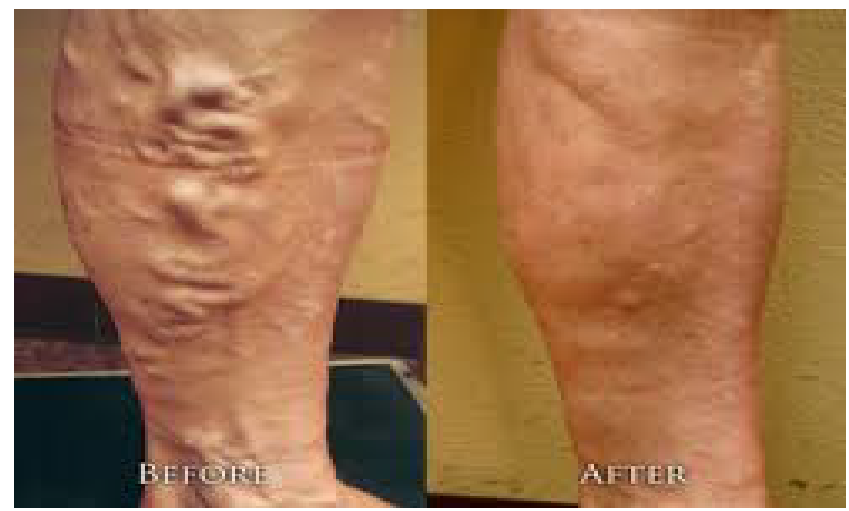

Figure 3: Result of UGFS in Lt Lower limb varicose veins.

\section{Complications}

Regarding complication there is statistically significant difference between groups regarding complications as hyperpigmentation, telangiectasia matting, headache, thrombophlebitis, infection, pain at site of injection, parathesis and haematoma, but not statistically significant difference regarding DVT and PE. These differences between groups are because those complications are technique specific (Table 4).

\section{Discussion}

Varicose veins constitute a chronic, frequently relapsing event that develops secondary to valvular failure. It is, therefore, unrealistic to expect the complete and constant removal of superficial reflux in all patients subjected to a single treatment whether it was operative, UGFS, or another minimally invasive alternative [17].

Although still considered by many surgeons as the 'gold standard', the efficacy of operation is limited by fear of damaging the saphenous nerve, to strip the below knee great saphenous vein BK-GSV - a common cause of residual and recurrent disease as well. Furthermore, a redo surgery for residual or recurrent reflux is usually difficult, often morbid, and frequently associated with suboptimal patient outcomes [17].

For many years, high ligation and stripping of the GSV are the most commonly used and effective method for varicose veins management [18]. The operation is a traumatic experience for patients. Surgery may

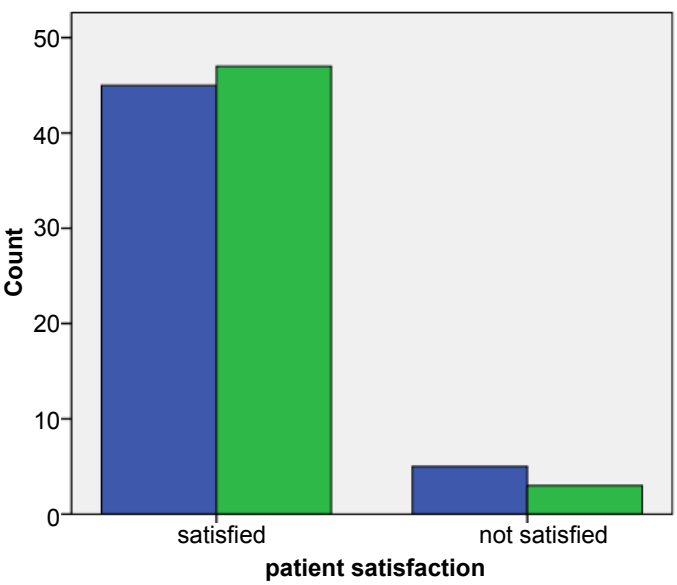

rocedure ㄴ. surge

Figure 4: Patient satisfaction between groups at 1 year.

\begin{tabular}{|c|c|c|c|c|c|c|}
\hline & & Sum of Squares & Df & Mean Square & $\mathbf{F}$ & Sig. \\
\hline VCSS & Between Groups & 1.440 & 1 & 1.440 & 0.665 & 0.417 \\
\hline VCSS at 1 month & Between Groups & 0.160 & 1 & 0.160 & 0.347 & 0.557 \\
\hline VCSS at 6 month & Between Groups & 0.090 & 1 & 0.090 & 0.285 & 0.594 \\
\hline VCSS at 1 year & Between Groups & 0.000 & 1 & 0.000 & 0.000 & 1.000 \\
\hline Follow up at 1 month & Between Groups & 0.490 & 1 & 0.490 & 2.713 & 0.103 \\
\hline Follow up at 6 months & Between Groups & 0.010 & 1 & 0.010 & 1.000 & 0.320 \\
\hline Follow up at 1 year & Between Groups & 0.010 & 1 & 0.010 & 0.031 & 0.860 \\
\hline Recurrence & Between Groups & 0.010 & 1 & 0.010 & 0.100 & 0.752 \\
\hline Patient satisfaction & Between Groups & 0.040 & 1 & 0.040 & 0.536 & 0.466 \\
\hline
\end{tabular}

Table 3: Difference between groups in follow up. 


\begin{tabular}{|l|c|c|}
\hline Complication & Surgery & Foam \\
\hline DVT & 0 & 1 \\
\hline PE & 0 & 1 \\
\hline Telangectatic matting & 0 & 4 \\
\hline Haematoma & 4 & 0 \\
\hline Groin infection & 2 & 0 \\
\hline Parathesia & 5 & 0 \\
\hline Pain at injection site & 0 & 6 \\
\hline Headache & 0 & 3 \\
\hline Hyperpigmentation & 0 & 5 \\
\hline Thrompophlipitis & 0 & 5 \\
\hline
\end{tabular}

also be followed by many complications as bleeding, groin infection, thrombophlebitis, saphenous nerve injury or even life-threatening conditions [19]. Additionally, postoperative recovery is quite long. General or regional anesthesia during a conventional operation increases the costs of treatment [12].

In recent years many less aggressive methods of endovenous treatments of varicose veins, such as sclerotherapy, thermo ablation (radiofrequency, laser, steam ablation) and intravascular glue have been used. The first one who used foam sclerosant was Orbach in 1944 [20,21]. Cabrera et al. in 1997 performed ultrasound-guided sclerotherapy. Finally, Tessari presented the newest method of producing a foamy sclerosant in 2000 . He used two syringes and a three-way tap [22]. This method gave the opportunity to achieve stable foam formed of small bubbles. New treatment methods should be compared to surgery in order to measure their credibility and safety. The significance of randomized clinical trials for clinical decision making has been widely recognized [23].

Following surgery, recurrence rates after 2-5 years vary between 20 and 50\% [24-26] and recurrence following FS reflux was reported in $31 \%$ of the patients after 2 years [27]. We considered reflux combined with symptoms as the most relevant measure because it best reflects clinical practice, where patients are treated only if they exhibit a combination of venous reflux and symptoms $[28,29]$.

The VCSS has been introduced only after 2004 therefore few studies are available for comparing outcomes after treatment using this scoring system [30].

In 2006 study shows VCSS, venous disability score VDS and CEAP clinical score were equally sensitive and better for measuring response to superficial venous surgery [31]. Very few studies have compared UGFS with surgery in a randomised study [32,33]. In the study by Masuda et al. they compared the change in VVCSS after foam sclerotherapy and found that median score changes from 8 to 2 (75\% change in score) [34]. Iafrati et al. compare the change in VCSS after surgery and found that mean VCSS change from 9.8 to 4.2 (57\% change in score) [35].

Gloviczki et al. also compared the change in VCSS after surgery and found that mean VCSS change from 8.93 to 3.98 (55\% change in score) after the treatment [36].

Figueiredo et al. compared the result of foam sclerotherapy with surgery on the basis of VCSS they found improvement in both groups in VCSS in 1 month and 6 months follow up [32].

However, there is very little data in literature directly comparing UGFS with surgery on the basis of VCSS, in our work both treatment modalities were directly compared by using VCSS and both modalities were equally effective in improving the VCSS score at 1 and 6 month and 1 year with no significant difference between foam and surgery groups.

Regarding vein occlusion rate, based on 69 studies in systemic review done by Jia et al. [37], the median rate of target vein occlusion was $87 \%$ (range 60-98). In another study done by Cabrera et al. [38], $81 \%$ of the treated GSV with foam therapy remained occluded after 3 years or more. Also, Thomasset et al. [39] reported that, with 3 months as a median time of follow up $79 \%$ of cases showed complete occlusion of desired veins, $14 \%$ showed partial occlusion and the rest $6 \%$ showed complete patency. Figueiredo et al. shows the obliteration rate of $90 \%$ in surgery group and $78 \%$ in foam sclerotherapy group after 6 month of follow up [32]. Their study also, reported that the great saphenous vein treated vessels in sclerotherapy group showed a success rate $80 \%$. In the study done by O'Hare et al. [40] the target vein occlusion was $93 \%$ by Doppler at 2 weeks follow up and $74 \%$ by Duplex at six month follow up. The treated veins in their study included the great saphenous vein (GSV), small saphenous vein (SSV), anterior accessory saphenous vein (AASV) or other recurrent veins with significant proximal incompetent deep venous connection. In the Tessari group, they found immediate success in $93.3 \%$.

Hamel-Desnos et al. [41] reported the outcome of comparing liquid and foamed 3\% polidocanol. In the foam group, $84 \%$ of the 45 patients had no residual reflux at 3 weeks. At 6 months, there were two recanalization in the foam group. A recent meta-analysis reported the outcome of 13 studies that assessed surgery and 10 studies where patients with VV underwent USGFS with an average follow-up of 32.2 months [27]. The estimated pooled success rates (with $95 \%$ confidence intervals) were $78 \%$ (70-84\%) for surgery and $77 \%$ (69-84\%) for USGFS It concluded that in the absence of large, comparative randomized clinical trials, foam sclerotherapy appears to be at least as effective as surgery in the treatment of lower extremity VV.

Dwerryhouse et al. did a follow-up study of 78 patients (110 limbs) who had primary GSV varicosities and underwent saphenofemoral ligation (SFL) alone or combined with stripping. At 5 years they found that stripping decreased the risk of redo surgery by two-thirds. Although surgery is highly effective in the short-term, the long-term recurrence rates are approximately $30 \%$ [42]. In another trial [43], saphenous reflux was abolished in $85 \%$ of surgery patients and $84 \%$ of foam sclerotherapy patients 1 year after treatment. Bountouroglou et al. found an obliteration rate of $89 \%$ in surgery and $78 \%$ in foam sclerotherapy group after 12 month of follow up [44].

Several large case series and one multicenter study have been published. UGFS in 1411 limbs showed occlusion in 88\% of GSVs after a mean follow-up of 11 months [45-47]. Few studies showed $69 \%$ complete sclerosis in 99 limbs after 24 months of follow-up [48], $44 \%$ occlusion in 211 limbs after 5 years of follow-up [43] and $88 \%$ occlusion in 143 limbs after 6 weeks of follow-up [49]

Our study compared 1 year results of surgery and ultrasound guided foam sclerotherapy but we should notice that all our patients as mentioned in inclusion criteria had been diagnosed as C2-3 EpAsPr. Our results were as follow at 1 year follow up both foam and surgery groups achieved $88 \%$ total occlusion of GSV and our result are comparable with some other studies.

\section{Complications}

Some complications were exclusive to surgery group and not found on UGFS group. These included stitch infection in $3(12 \%)$ 
patients, seroma in $3(12 \%)$ and hematoma in $2(8 \%)$ subjects at 1 week follow up Figueiredo et al. in 2009 describes infection, hematoma and suture dehiscence in surgery group respectively in $3 \%, 7 \%$ and $38 \%$ patients [32]. In the present study surgical complications were groin haematoma in 4 patient $8 \%$, groin infection in 2 patient $4 \%$ and parathesis in 5 patients $10 \%$ and all these complication were transient and managed in conservative way while in foam group complications in were pain at injection site in 6 patient $12 \%$, hyperpigmentation and thrombophlebitis seen in 5 patients $10 \%$, telangiectasia matting seen in 4 patients $8 \%$, headache in 3 patients $6 \%$ and deep venous thrombosis and pulmonary embolism seen in one case $2 \%$. In our work, complications in the foam UGFS group were tolerable and transient and did not need any active intervention, which are again comparable to the published studies $[37,50,51]$.

Except for one case of DVT and pulmonary embolism which was managed medically without intervention and after 3 month anticoagulant complete resolution was achieved. The $2 \%$ frequency of thromboembolic events in our subjects corresponds to reported thromboembolic event rates between $0.02 \%$ and $1.25 \%[52,53]$.

In a study by Myers et al. [54], the only complication observed was deep venous thrombosis DVT, which occurred in $3.2 \%$ of the patients. This is somewhat higher than what has been reported in our study. Jia et al. [37] showed pain and pigmentations were the two most important complications in foam group which is in accordance with the literature, pain in $4(16 \%)$ patients and pigmentation $5(20 \%)$ patients $[51,52]$.

Ouvry et al. show Pain and pigmentations were the most two important complications in foam [50]. Guex et al. Pain and pigmentations were the most two important complications in foam sclerotherapy [51].

Thomasset et al. show that the most common side effects associated with foam sclerotherapy were skin discoloration in 30\% patients, superficial thrombophlebitis in $16 \%$, and an allergy to the foam sclerosant in $2.5 \%$ [39]

In a study by Smith [55], the reported complications were as follow. Thrombophlebitis occurred in a small number of patients (5\%), and was managed by using analgesia, compression, and aspiration of the thrombus. Calf vein thrombosis was confined to isolated gastrocnemius veins or to part of the posterior tibiae vein (1.23\%), which was managed with compression by stocking, or bandage and exercise without using anticoagulants.

\section{Limitation}

The main limitations of the present study are the few number of patients assessed and the short period of follow-up. On the other hand, the fact that we were working with a homogeneous sample (all patients classified as Cc2-3 EpAsPr) allowed discussing the treatment of this specific type of patients. Further work should be done with the aim of defining a more accurate classification profile.

\section{Conclusion}

Our study declared that UGFS is effective in obliterating saphenous trunks. Follow-up treatment modalities foam and surgery accomplished similar refinements in the VCSS. The anatomical success rate was similar for both modalities. However, these early results cannot be relied on to determine definitive recommendations varicose veins management as late recurrence rates and the need for further management also required to be considered.

\section{Conflict of Interest}

There is no conflict of interest.

\section{References}

1. Wong JK, Duncan JL, Nichols DM (2003) Whole-leg duplex mapping for varicose veins: observations on patterns of reflux in recurrent and primary legs, with clinical correlation. Eur J Vasc Endovasc Surg 25: 267-275

2. Evans CJ, Fowkes FG, Ruckley CV, Lee AJ (1999) Prevalence of varicose veins and chronic venous insufficiency in men and women in the genera population: Edinburgh Vein Study. J Epidemiol Community Health 53: 149-153.

3. Eberhardt RT, Raffetto JD (2005) Chronic venous insufficiency. Circulation 111: 2398-2409.

4. Hobbs JT (1974) Surgery and sclerotherapy in the treatment of varicose veins A random trial. Arch Surg 109: 793-796.

5. Lofgren KA, Ribisi AP, Myers TT (1958) An Evaluation of Stripping Versus Ligation for Varicose Veins. Ama Arch Surg 76: 310-316.

6. Van Rij AM, Jiang P, Solomon C, Christie RA, Hill GB (2003) Recurrence after varicose vein surgery: a prospective long-term clinical study with duplex ultrasound scanning and air plethysmography. J Vasc Surg 38: 935-943.

7. Fischer R, Linde N, Duff C, Jeanneret C, Chandler JG, et al. (2001) Late recurrent saphenofemoral junction reflux after ligation and stripping of the greater saphenous vein. J Vasc Surg 34: 236-240.

8. Neglen $P$ (2001) Long saphenous stripping is favored in treating varicose veins Dermatol Surg 27: 901-902.

9. Kanwar A, Hansrani M, Lees T, Stansby G (2010) Trends in varicose vein therapy in England: radical changes in the last decade. Ann R Coll Surg Eng 92: $341-346$

10. Rabe E, Otto J, Schliephake D, Pannier F (2008) Efficacy and safety of great saphenous vein sclerotherapy using standardized polidocanol foam (ESAF) a randomised controlled multicentre clinical trial. Eur J Vasc Endovasc Surg 35: $238-245$

11. Yamaki T, Nozaki M, Iwasaka S (2004) Comparative study of duplex-guided foam sclerotherapy and duplex-guided liquid sclerotherapy for the treatment of superficial venous insufficiency. Dermatol Surg 30: 718-722.

12. Rasmussen LH, Lawaetz M, Bjoern L, Vennits B, Blemings A, et al. (2011) Randomized clinical trial comparing endovenous laser ablation, radiofrequency ablation, foam sclerotherapy and surgical stripping for great saphenous varicose veins. Br J Surg 98: 1079-1087.

13. Hamel C, Ouvry P, Benigni JP, Boitelle G, Schadeck MP, et al. (2007) Comparison of $1 \%$ and $3 \%$ polidocanol foam in ultrasound guided sclerotherapy of the great saphenous vein: a randomised, double-blind trial with 2 year-followup. 'The 3/1 Study'. Eur J Vasc Endovasc Surg 34: 723-729.

14. Barrett JM, Allen B, Ockelford A, Goldman MP (2004) Microfoam ultrasoundguided sclerotherapy treatment for varicose veins in a subgroup with diameters at the junction of $10 \mathrm{~mm}$ or greater compared with a subgroup of less than 10 $\mathrm{mm}$. Dermatol Surg 30: 1386-1390.

15. Beale RJ, Gough MJ (2005) Treatment options for primary varicose veins--a review. Eur J Vasc Endovasc Surg 30: 83-95.

16. Darvall KA, Bate GR, Adam DJ, Bradbury AW (2009) Recovery after ultrasoundguided foam sclerotherapy compared with conventional surgery for varicose veins. Br J Surg 96: 1262-1267.

17. Kundu S, Lurie F, Millward SF, Padberg F, Vedantham S, et al. (2007) Recommended reporting standards for endovenous ablation for the treatment of venous insufficiency: joint statement of the American Venous Forum and the Society of Interventional Radiology. J Vasc Surg 46: 582-589.

18. Morales CG, Moreno EA, Aguayo AJ (2011) Compression therapy after varicose vein surgery. Can the classic elastic bandage be improved upon? Cir Esp 89: 629-630.

19. Perkins JM (2009) Standard varicose vein surgery. Phlebology 1: 34-41.

20. Orbach EJ (1944) Sclerotherapy of varicose veins: Utilisation of an intravenous air-block. Am J Surgery 66: 362-366.

21. Khachatryan V, Sirunyan AM, Tumasyan A, Adam W, Asilar E, et al. (2017) Measurement of the production cross section of a W boson in association with two b jets in pp collisions at [Formula: see text]. Eur Phys J C Part Fields 77: 92. 
Citation: Gamal WM, Mohamed AF (2017) Duplex Guided Foam Sclerotherapy Versus Surgery in Management of Primary Varicose Veins. J Vasc Med Surg 5: 325. doi: 10.4172/2329-6925.1000325

Page 7 of 7

22. Tessari L (2000) Nouvelle technique d'obtention de la sclero-mousse. Phlebologie 53: 129 .

23. Claxton K, Sculpher M, Drummond M (2002) A rational framework for decision making by the National Institute for Clinical Excellence (NICE). Lancet 360: $711-715$

24. Jones L, Braithwaite BD, Selwyn D, Cooke S, Earnshaw JJ (1996) Neovascularisation is the principal cause of varicose vein recurrence: Results of a randomised trial of stripping the long saphenous vein. Eur J Vasc Endovasc Surg 442: 12-15

25. Lurie F, Creton D, Eklof B Kabnick LS, Kistner RL, et al. (2003) Prospective randomized study of endovenous adiofrequency obliteration (closure procedure) vs ligation and stripping in a selected patient population (EVOLVES Study). J Vasc Surg 38: 207-214

26. Lurie F, Creton D, Eklof B. (2005) Ambulatory venous pressure: correlation with skin condition and role in identifying surgically correctible disease. Eur $\mathrm{J}$ Vasc Endovasc Surg 29: 67-73.

27. Van den Bos R, Arends L, Kockaert M, Neumann M, Nijsten T (2009) Endovenous therapies of lower extremity varicosities: a meta-analysis. J Vasc Surg 49: 230-239.

28. Blaise S, Bosson JL, Diamand JM (2010) Ultrasound-Guided Sclerotherapy of the Great Saphenous Vein with $1 \%$ vs. $3 \%$ Polidocanol Foam: A Multicentre Double-Blind Randomised Trial with 3-Year Follow-Up. Eur J Vasc Endovasc Surg 39: 779-86

29. Darke SG, Baker SJ (2006) Ultrasound-guided foam sclerotherapy for the treatment of varicose veins. Br J Surg 93: 969-974.

30. Eklöf B, Rutherford RB, Bergan JJ, Carpentier PH, Gloviczki P, et al. (2004) Revision of the CEAP classification for chronic venous disorders: consensus statement. J Vasc Surg 40: 1248-1252.

31. Kakkos SK, Rivera MA, Matsagas MI, Lazarides MK, Robless P, et al. (2003) Validation of the new venous severity scoring system in varicose vein surgery. J Vasc Surg 38: 224-228

32. Figueiredo M, Araújo S, Barros N, Miranda $F$ (2009) Results of surgical treatment compared with ultrasound-guided foam sclerotherapy in patients with varicose veins: a prospective randomised study. Eur J Vasc Endovasc Surg 38: 758-763.

33. Michaels JA, Campbell WB, Brazier JE (2006) Clinical trial, observational study and assessment of costeffectiveness of the treatment of varicose veins (REACTIV trial). Health Technology Assessment 10: 1-196.

34. Masuda EM, Kessler DM, Lurie F, Puggioni A, Kistner RL, et al. (2006) The effect of ultrasound-guided sclerotherapy of incompetent perforator veins on venous clinical severity and disability scores. J Vasc Surg 43: 551-556.

35. lafrati MD, Pare GJ, Donnell TF, Estes J (2002) Is the nihilistic approach to surgical reduction of superficial and perforator vein incompetence for venous ulcer justified? J Vasc Surg 36: 1167-1174

36. Gloviczki P, Bergan JJ, Rhodes JM, Canton LG, Harmsen S, et al. (1999) Mid-term results of endoscopic perforator vein interruption for chronic venous insufficiency: lessons learned from the North American subfascial endoscopic perforator surgery registry. The North American Study Group. J Vasc Surg 29 489-502.

37. Jia X, Mowatt G, Burr JM, Cassar K, Cook J, et al. (2007) Systematic review of foam sclerotherapy for varicose veins. Br J Surg 94: 925-936

38. Cabrera J, Cabrera J, Garcia-Olmedo MA (2000) Treatment of varicose long saphenous veins with sclerosant in microfoam form: long-term outcomes. Phlebology 15:19-23.

39. Thomasset SC, Butt Z, Liptrot S, Fairbrother BJ, Makhdoomi KR (2010) Ultrasound guided foam sclerotherapy: factors associated with outcomes and complications. Eur J Vasc Endovasc Surg 40: 389-392.

40. O'Hare JL, Parkin D, Vandenbroeck CP, Earnshaw JJ (2008) Mid term results of ultrasound guided foam sclerotherapy for complicated and uncomplicated varicose veins. Eur J Vasc Endovasc Surg 36: 109-113.
41. Hamel-Desnos C, Desnos P, Wollmann JC, Ouvry P, Mako S, et al. (2003) Evaluation of the efficacy of polidocanol in the form of foam compared with liquid form in sclerotherapy of the greater saphenous vein: Initial results. Dermatol Surg 29: 1170-1175.

42. Dwerryhouse S, Davies B, Harradine K, Earnshaw JJ (1999) Stripping the long saphenous vein reduces the rate of reoperation for recurrent varicose veins: five-year results of a randomized trial. J Vasc Surg 29: 589-592.

43. Wright D, Gobin JP, Bradbury AW, Coleridge-Smith $\mathrm{P}$, Spoelstra H, et al. (2006) Varisolve polidocanol microfoam compared with surgery or sclerotherapy in the management of varicose veins in the presence of trunk vein incompetence: European randomized controlled trial. Phlebology 21: 180-190.

44. Bountouroglou DG, Azzam M, Kakkos SK, Pathmarajah M, Young P, et al. (2006) Ultrasound-guided foam sclerotherapy combined with sapheno-femora ligation compared to surgical treatment of varicose veins: early results of a randomised controlled trial. Eur J Vasc Endovasc Surg 31: 93-100.

45. Benigni JP, Sadoun S, Thirion V, Sica M, Demagny A, et al. (1999) Telangiectasies et varices reticularires. Traitement par la mouse d Aetoxisclerol a $0.25 \%$ presentation dune etude pilote. Phlebologie 52: 283-290.

46. Geroulakos $\mathrm{G}$ (2005) Foam therapy for those with varicose vein. Dermatol Surg 50: 89-94.

47. Breu FX, Guggenbichler S (2004) European Consensus Meeting on Foam Sclerotherapy, April, 4-6, 2003, Tegernsee, Germany. Dermatol Surg 30: 709-717.

48. Rybak $Z$ (2003) Foam obliteration of insufficient perforating veins in patients suffering from leg ulcers. Phlebolymphology.

49. Hartmann K, Klode J, Pfister R, Toussaint M, Weingart I, et al. (2006) Recurren varicose veins: sonography-based re-examination of 210 patients 14 years after ligation and saphenous vein stripping. Vasa 35: 21-26.

50. Ouvry P, Allaert FA, Desnos P, Hamel-Desnos C (2008) Efficacy of polidocano foam versus liquid in sclerotherapy of the great saphenous vein: a multicentre randomized controlled trial with a 2- year follow-up. Eur J Vasc Endovasc Surg 36: $366-370$

51. Guex JJ, Schliephake DE, Otto J, Mako S, Allaert FA (2010) The French polidocanol study on long-term side effects: a survey covering 3,357 patien years. Dermatol Surg 36 Suppl 2: 993-1003.

52. Ceulen RP, Bullens-Goessens YI, Pi-Van de Venne SJ, et al. (2007) Outcomes and side effects of duplexguided sclerotherapy in the treatment of great saphenous veins with $1 \%$ versus $3 \%$ polidocanol foam: results of a randomized controlled trial with 1-year follow-up. Dermatol Surg 33: 276-281.

53. Guex JJ, Allaert FA, Gillet JL, Chleir F (2005) Immediate and midterm complications of sclerotherapy: report of a prospective multicenter registry of 12,173 sclerotherapy sessions. Dermatol Surg 31: 123-128.

54. Myers KA, Jolley D, Clough A, Kirwan J (2007) Outcome of ultrasound-guided sclerotherapy for varicose veins: medium-term results assessed by ultrasound surveillance. Eur J Vasc Endovasc Surg 33: 116-121.

55. Smith PC (2006) Chronic venous disease treated by ultrasound guided foam sclerotherapy. Eur J Vasc Endovasc Surg 32: 577-583. 